\title{
Uptake of intermittent preventive treatment and pregnancy outcomes: health facilities and community surveys in Chókwè district, southern Mozambique
}

Paulo Arnaldo 1,2,3, Eduard Rovira-Vallbona', Jerónimo S. Langa ${ }^{2}$, Crizolgo Salvador ${ }^{2}$, Pieter Guetens ${ }^{1}$, Driss Chiheb ${ }^{1}$, Bernardete Xavier ${ }^{2}$, Luc Kestens ${ }^{1,3}$, Sónia M. Enosse ${ }^{2}$ and Anna Rosanas-Urgell ${ }^{1 *}$ (D)

\begin{abstract}
Background: Malaria in pregnancy leads to serious adverse effects on the mother and the child and accounts for 75,000-200,000 infant deaths every year. Currently, the World Health Organization recommends intermittent preventive treatment of malaria in pregnancy (IPTp) with sulfadoxine-pyrimethamine (SP) at each scheduled antenatal care (ANC) visit. This study aimed to assess IPTp-SP coverage in mothers delivering in health facilities and at the community. In addition, factors associated with low IPTp-SP uptake and malaria adverse outcomes in pregnancy were investigated.
\end{abstract}

Methods: A community and a health facility-based surveys were conducted in mothers delivering in Chókwè district, southern Mozambique. Social-demographic data, malaria prevention practices and obstetric history were recorded through self-report and antenatal records. For women delivering at health facilities, a clinical examination of mother and child was performed, and malaria infection at delivery was determined by rapid diagnostic test, microscopy, quantitative PCR and placental histology.

Results: Of 1141 participants, 46.6, 30.2, 13.5 and 9.6\% reported taking $\geq 3$, two, one and none SP doses, respectively. Low IPTp uptake ( $<3$ doses) was associated with non-institutional deliveries $(A O R=2.9, P<0.001)$, first $A N C$ visit after week $28(\mathrm{AOR}=5.4, \mathrm{P}<0.001)$, low awareness of IPTp-SP $(\mathrm{AOR}=1.6, \mathrm{P}<0.002)$ and having no or only primary education $(A O R=1.3, P=0.041)$. The overall prevalence of maternal malaria (peripheral and/or placental) was $16.8 \%$ and was higher among women from rural areas compared to those from urban areas ( $A O R=1.9, P<0.001)$. Younger age $(<20$ years; $A O R=1.6, P=0.042)$ and living in rural areas $(A O R=1.9, P<0.001)$ were predictors of maternal malaria at delivery. Being primigravidae $(A O R=2.2, P=0.023)$ and preterm delivery $(A O R=2.6, P<0.001)$ predicted low birth weight while younger age was also associated with premature delivery $(A O R=1.4, P=0.031)$.

Conclusion: The coverage for two and $\geq 3$ doses of IPTp-SP is moderately higher than estimates from routine health facility records in Gaza province in 2015. However, this is still far below the national target of $80 \%$ for $\geq 3$ doses. Ongoing campaigns aiming to increase the use of malaria prevention strategies during pregnancy should particularly target rural populations, increasing IPTp-SP knowledge, stimulate early visits to ANC, improve access to health services and the quality of the service provided.

Keywords: Malaria, Pregnancy, IPTp-SP, Coverage, Risk factors, Mozambique

\footnotetext{
*Correspondence: arosanas@itg.be

1 Department of Biomedical Sciences, Institute of Tropical Medicine

Antwerp, Antwerp, Belgium

Full list of author information is available at the end of the article
} 


\section{Background}

Although the global burden of malaria has been considerably reduced over recent years, it remains a major public health problem in sub-Saharan Africa (SSA), where 190 million cases and 394,680 deaths occurred in 2015 [1]. It is estimated that in the SSA region, 32 million pregnant women are at risk of acquiring malaria in pregnancy (MiP) every year $[2,3]$.

MiP is associated with increased risk of both maternal and neonatal adverse outcomes including maternal anaemia (which leads to increased maternal mortality), delivery of low birth weight (LBW) infants, premature delivery, stillbirth and increased perinatal and infant mortality $[4,5]$. Women in their first pregnancy are at high risk of infection due to lack of specific immunity against the Plasmodium falciparum variant surface antigen VAR2csa, that mediates specific sequestration of parasites to placental tissue [6, 7].

To prevent MiP in areas with moderate to high malaria transmission the World Health Organization (WHO) recommends the use of insecticide-treated nets (ITNs) and intermittent preventive treatment in pregnancy (IPTp) with at least three doses of sulfadoxine-pyrimethamine (SP), administered at scheduled antenatal care (ANC) visits regardless of the presence of parasites and signs of malaria [8]. Despite the fact that IPTp-SP has been rolled out for many years in SSA countries, several studies in the region report a low IPTp-SP coverage [9, $10]$. In 2015 , only $50 \%$ of women in 36 reporting countries in the African region received two SP doses, while only $31 \%$ received $\geq 3$ doses [2]. The major factors that have been associated with low IPTp-SP uptake include the number and timing of ANC visits, the lack of knowledge of MiP adverse consequences [11], systemic factors such as lack of clear policies and guidelines, as well as insufficient training, supervision, and quality assurance at the health facility level $[10,12-14]$ and drug stockouts [15]. In addition, women that have non-institutional deliveries (deliveries at home) may be more likely to benefit less from health care including prenatal consultations and hence, receive less IPTp-SP doses [16, 17].

In Mozambique, where malaria is endemic and transmission is perennial, MiP is the most important cause of maternal death and contributes to the high overall maternal mortality rates (408 of maternal mortality per 100,000 births in 2011) [18] and delivery of LBW infants (4.3\% overall in 2016) observed in the country [19]. IPTp-SP was first implemented in the country in 2006 delivered free of charge to all pregnant women under directlyobserved treatment (DOT) [20]. In 2014, the national guidelines were updated and implemented countrywide to adjust to the current $\geq 3$ SP-dose WHO recommendation [21]. Although the collection of robust data on IPTp coverage is essential to monitor, evaluate and further improve the currently implemented MiP interventions, in Mozambique IPTp coverage available data is based mainly on routine annual reports from health centres (often lacking completeness and accuracy) [21], household surveys $(\mathrm{HH})$ of HIV and malaria indicators at the province level [22] and retrospective studies (which do not reflect the current situation) [15].

In 2015, a national HH survey with data collection at the provincial level, reported an IPTp-SP country coverage of $51.4 \%$ for one dose, $34.2 \%$ for two doses and $22.4 \%$ for $\geq 3$ doses [22]. This study was conducted to determine the coverage of IPTp-SP uptake in Chókwè district (Gaza Province), where malaria prevalence in the general population was reported at $32.5 \%$ in 2016 (Chókwè district health services 2016, unpublished data), at the time of implementation of the new WHO recommendation of IPTp. Importantly, the study collected information on factors potentially related to low IPTp-SP uptake both in health facilities and at the community level (among women with non-institutional deliveries). In addition, on these mothers delivering at the health facility, factors associated with malaria infection at delivery and adverse pregnancy outcomes were also investigated.

\section{Methods \\ Study site}

This study was conducted in the Chókwè district between June 2014 and June 2015. Chókwè is located in Gaza Province along the Limpopo River in the southern region of Mozambique, approximately 220 kilometres northwest of Maputo, the capital city of the country. The district has an area of $2466 \mathrm{~km}^{2}$ and an estimated population of 214,183 inhabitants [23]. Chókwè district includes four administrative areas: Chókwè, Liónde, Macarretane and Xilembene (Fig. 1). The main economic activities of the district population are subsistence farming, large rice productions supported by major irrigation systems, livestock keeping and small business. Malaria, which is mostly attributable to $P$. falciparum, is endemic in this area with the majority of cases occurring during the rainy season from November to April.

A continuous health and demographic surveillance system (HDSS)-including 135,616 habitants (63.3\% of the district population) and occupying an area of approximately $600 \mathrm{~km}^{2}$ within a $25 \mathrm{~km}$ radius of Chókwè City is run by the "Centro de Investigação e Treino em Saúde de Chókwè", a clinical research centre affiliated with the National Institute of Health-Ministry of Health of Mozambique. The HDSS catchment area includes fifteen villages, eight of which belong to the Chókwè Municipality (classified as urban) and seven to Liónde and Macarretane (classified as rural). Data routinely registered in 


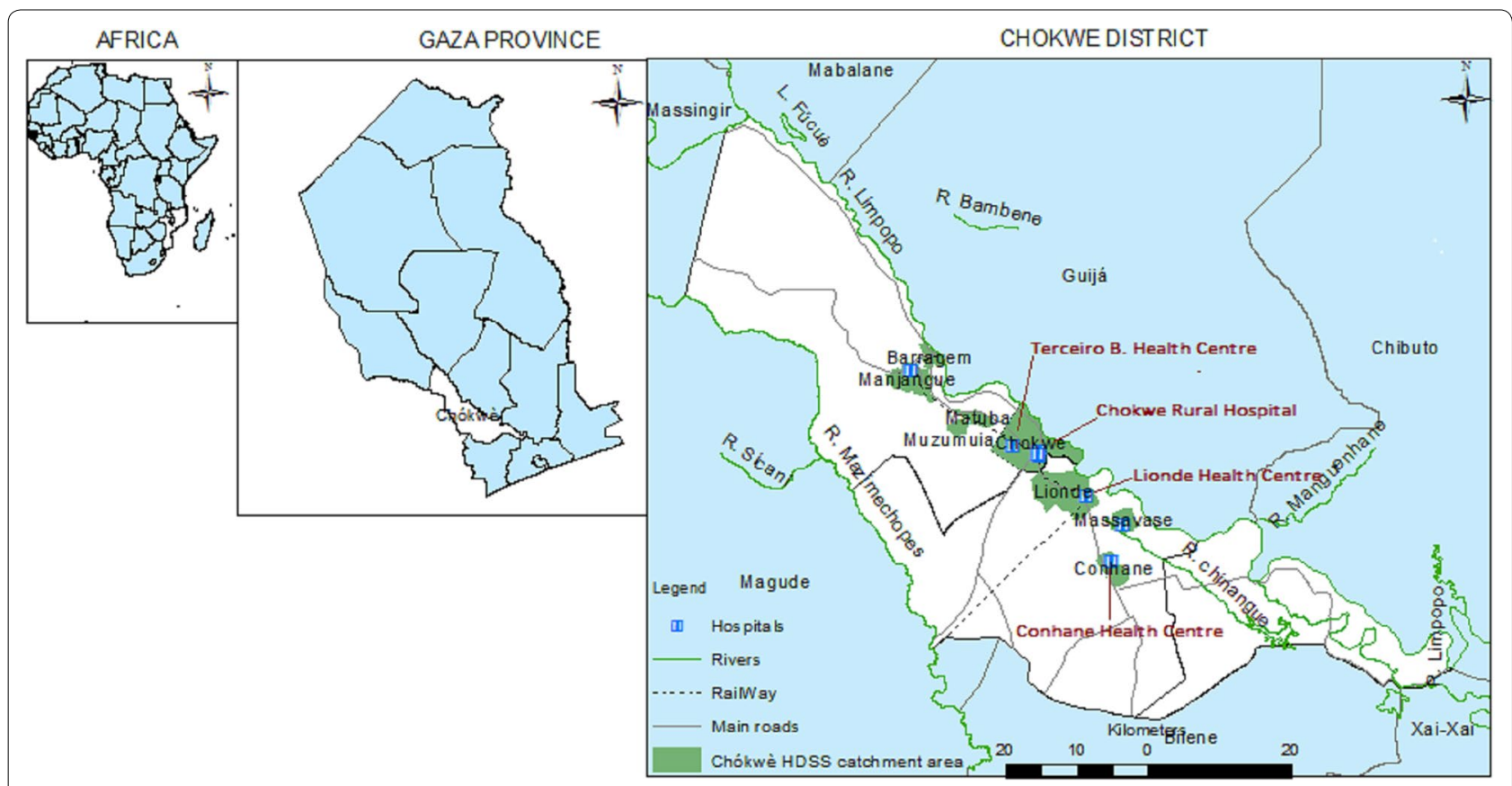

Fig. 1 Map of Chókwè district showing the Chókwè HDSS catchment area and study Health Centres (Source: Chókwè HDSS 2014)

the HDSS includes migrations, pregnancies, births and deaths (Bonzela et al. pers.comm.).

\section{Study design and population}

Although during the last 10 years Mozambique has achieved significant progress in the coverage of institutional deliveries, an important proportion of these still occur mainly in rural communities $[18,19,22]$. Therefore, to obtain accurate data on IPTp coverage in the area under HDSS surveillance, a community and health facility based surveys were conducted. The community survey included women with non-institutional deliveries during the study period, while the health facility survey included women delivering at (i) Chókwè Hospital, (ii) Peripheral Health Centre of Terceiro Bairro, (iii) Peripheral Health Centre of Liónde and (iv) Peripheral Health Centre of Conhane, all located within the Chókwè HDSS catchment area (Fig. 1). Chókwè Hospital is located in urban area (Chókwè municipality) and is the reference hospital providing assistance for all Chókwè district population and neighbouring districts.

Women were enrolled in the study if they fulfilled the following inclusion criteria: (i) aged between 15 and 48 years, (ii) having a singleton delivery, and (iii) being a permanent resident of the area under HDSS surveillance in the Chókwè district. HIV positive women receiving antiretroviral treatment or prophylactic treatment with co-trimoxazole were excluded from the study, since IPTp$\mathrm{SP}$ is not recommended in these women due to potential adverse drug reactions [24]. Written informed consents were obtained from all women before enrolment into the study.

\section{Sample size}

In Mozambique, WHO's recommendation of at least three doses of IPTp-SP during pregnancy was implemented in 2014. Therefore, the sample size calculation was based on the estimate of the proportion of pregnant women receiving three or more IPTp-SP in Gaza province. This was approximately $28 \%$ in 2014 [21]. With a margin of error of $\pm 4 \%$ using an alpha type- 1 error of $5 \%$, at least 1038 delivering women during the study period were estimated to be included.

\section{Data collection and study procedures}

Data were collected by trained midwives and HDSS health-workers who were specifically trained for this study. A structured questionnaire in Portuguese and local Changana language was administrated to document socio-demographic data including age, residence, marital status, education, occupation, knowledge of IPTp and use of ITN. Antenatal data were obtained from the mother's antenatal card and included parity, gestational age at the first ANC, and timing of IPTp-SP doses. Women with non-institutional deliveries were identified through the HDSS by comparing births registered in the database and hospital registers, and the interviews were conducted 
within 3 months after the date of delivery to minimize recall bias.

In the health facility survey, parturient women were examined by a hospital clinician. Axillary body temperature was recorded and $3 \mathrm{ml}$ of venous blood sample was collected immediately after delivery in ethylene diamine tetra acetic acid (EDTA) containing tubes. Peripheral venous blood samples were used to assess hemoglobin levels (HemoCue 301, Angelholm, Sweden), P. falciparum infection using RDT (SD Bioline Malaria Antigen Pf, Standard Diagnostic Inc, South Korea) and to prepare blood slides and samples for posterior diagnosis by light microscopy and quantitative polymerase chain reaction (qPCR), respectively.

Newborn's birth weight and gestational age were measured within $24 \mathrm{~h}$ after delivery: birth weight using a digital scale (Soehnle professional, Soehnle Industrial Solutions GmbH; Germany) and gestational age based on last normal menstrual period; in case of uncertainty, it was estimated with the Ballard score maturational assessment by trained midwives [25]. Placental tissue samples were collected from the maternal side of the placenta with approximately $2 \mathrm{~cm} \times 2 \mathrm{~cm}$ in length and width, and $1 \mathrm{~cm}$ in depth and immediately placed in $10 \%$ neutral buffer formalin and stored at $2-8{ }^{\circ} \mathrm{C}$ until processed.

\section{Laboratory procedures}

Thick and thin smears were prepared and stained with $5 \%$ Giemsa for $25 \mathrm{~min}$ and examined for malaria parasites by standard microscopy [26]. Slides were examined by two independent microscopists from the National Malaria Reference Laboratory using light microscopy at $100 \times$ magnification for the presence of malaria parasites. Parasite density was estimated by counting the number of asexual parasites per 500 white blood cells (WBCs), and parasites per $\mu \mathrm{L}$ calculated assuming a WBC count of 8000 cells per $\mu \mathrm{L}$ of whole blood. A slide was considered to be negative if no parasites were seen after review of 1000 WBCs. In case of discrepant results, the slide was read by a third microscopist and the mean of the two closest reads was used. External quality control with $10 \%$ of slides was performed by a fourth experienced reader at the Malariology Unity Laboratory, Institute of Tropical Medicine in Antwerp, Belgium.

Molecular detection of $P$. falciparum infections was performed by qPCR. Briefly, DNA was extracted from $200 \mu \mathrm{L}$ of erythrocyte pellet with QIAamp 96 DNA blood kit (Qiagen, Germany), and eluted in $200 \mu \mathrm{L}$ of water. Five microliters of DNA were used for qPCR analysis targeting $P$. falciparum var gene acidic terminal sequence (var ATS, 59 copies per genome) as previously described [27]. Parasite densities were obtained by interpolating cycle thresholds $(\mathrm{Ct})$ from a standard curve of infected erythrocytes diluted in whole blood (from 100,000 to 0.01 parasites $/ \mu \mathrm{L})$. Samples with $\mathrm{Ct}$ values $\leq 38.5 \mathrm{Ct}$ were considered positive. The limit of detection was 0.04 parasite $/ \mu \mathrm{L}$.

Placental tissue preparation and histological examination was performed at the Pathology laboratory of the Maputo Central Hospital (Hospital Central de MaputoHCM) as described elsewhere [28]. Two trained-independent microscopists read the slides, discrepant results were reviewed by a third microscopist and a consensus result was determined. External quality control was performed at Barcelona Institute for Global Health (ISGlobal) by a fourth experienced reader for $10 \%$ of slides.

\section{Definitions}

The following definitions were used: (a) fever: axillary temperature $\geq 37.5{ }^{\circ} \mathrm{C}$; (b) moderate and severe anaemia: $\mathrm{Hb}<11 \mathrm{~g} / \mathrm{dL}$ and $\mathrm{Hb}<8 \mathrm{~g} / \mathrm{dL}$ respectively; (c) LBW: $<2,500 \mathrm{~g}$; (d) preterm delivery: $<37$ weeks of completed gestation. Gravidity was categorized into primigravidae (women in their first pregnancy) and multigravidae (women in their second or more pregnancies). Placental infection was classified according to the histopathology results as: (i) uninfected, no parasites or pigment present; (ii) acute infection, parasites present with no pigment in monocytes or fibrin; (iii) chronic infection, parasites present in erythrocytes with pigment and (iv) past infection, no parasites, pigment confined to fibrin or cells within fibrin indicating past infection [29].

\section{Ethics statement}

This study was approved by the National Bioethics Committees of Mozambique (CNBS) (IRB00002657), the Institute of Tropical Medicine (ITM) Institutional Review Board (IRBAB/ac/059) and the University of Antwerp (IRB-B300201421228). All procedures were carried out in accordance with the Helsinki Declaration as revised in 2013. Administrative approval to conduct the study was obtained from the local health facilities and the Ministry of Health of Mozambique. Informed consent was obtained at recruitment from all study participants or their representatives.

\section{Statistical analysis}

Data from all study forms were double entered and checked for unusual values and inconsistencies between fields using OpenClínica v.3.3 (USA), and then exported to STATA version 14.1 (Stata Corp, College Station, TX, USA) for analysis. For categorical variables, descriptive analysis was performed and the data summarized in proportions and frequency tables. Means with their respective standard deviations and medians with interquartile 
ranges were used to summarize continuous variables. Kruskal-Wallis rank test was used to compare medians and interquartile ranges (IQRs) of continuous variables, and Chi square test or Fisher exact test for categorical variables. Univariate analysis was performed to analyse factors associated with low IPTp-SP uptake ( $<3$ doses), maternal malaria infection and density, LBW and preterm deliveries. Explanatory variables with $P<0.20$ in the univariate analysis, were included in the multivariable regression analysis. Crude odds ratios (OR), adjusted odds ratios (AOR) and 95\% confidence intervals are reported with $P$ values $<0.05$ considered statistically significant.

\section{Results}

\section{Characteristics of the study population (community} and health facility surveys)

During the study period, 3854 deliveries were registered in the HDSS catchment area. Of these, 1330 (34.5\%) women were screened and $14.2 \%(189 / 1330)$ were excluded due to HIV positivity, non-singleton birth or living outside the Chókwè district. In total, 1141 women were interviewed and included in the study, from which $80.1 \%(914 / 1141)$ were recruited in maternity hospitals and $19.9 \%(227 / 1141)$ in the community (non-institutional deliveries).

Demographic characteristics of study participants are shown in Table 1 (first and second columns). More than two-thirds $(70.6 \%)$ of the women included in the study lived in Chókwè municipality (urban area), compared to 29.4\% living in the rural areas of Lionde and Macarretane. Of the 227 women who had non-institutional deliveries, $67.0 \%$ were from rural areas, and $33.0 \%$ from urban area $(\mathrm{P}<0.001)$ (Additional file 1: Table $\mathrm{S} 1$ ).

In this study, 92.5\% (1055/1141) of women had their first ANC visit before 28 weeks (or during the first or second trimester of gestation). The majority of women starting ANC visit in the third trimester of gestation lived in urban areas $82.7 \%(71 / 86), 70.9 \%(61 / 86)$ had no formal education, $81.4 \%(70 / 86)$ were multigravidae, and $59.3 \%$ (51/86) delivered at Chókwè hospital, while 25.6\% $(22 / 86)$ delivered at peripheral health centres and $15.1 \%$ $(13 / 86)$ had non-institutional deliveries $(\mathrm{P}=0.011)$.

Compared to women delivering in health facilities, women with non-institutional deliveries (Table 1) showed a higher proportion of multigravida $(85.9 \%$ vs $56.8 \%$, $\mathrm{P}=0.017)$, were more likely to live in rural areas $(67.0 \%$ vs $20.0 \%, \mathrm{P}<0.001)$, had none or primary education only ( $86.8 \%$ vs $52.2 \%, \mathrm{P}<0.001)$ and mainly worked in agriculture or livestock $(62.6 \%$ vs $4.2 \%, \mathrm{P}<0.001)$. When women were questioned (open question) about the main reasons for not delivering at health facility their answers were: lack of transport (55.5\%), unexpected delivery date
(40.9\%), no nurse present at the hospital (1.3\%), lack of electricity in the maternity board (1.8\%), and desired to deliver at home (0.9\%).

\section{IPTp-SP coverage and factors associated with low uptake} Overall, $532(46.6 \%)$ women participating in the study received $\geq 3$ doses of IPTp-SP, 345 (30.2\%) received two doses, $154(13.5 \%)$ received one and $110(9.6 \%)$ received no IPTp-SP at all. Analysis of factors associated with low IPTp-SP uptake is presented in Table 2. In the univariate analysis, non-institutional delivery $(\mathrm{OR}=3.5, \mathrm{P}<0.001)$, place of residence $(\mathrm{OR}=1.7, \mathrm{P}<0.001)$, having no or only primary education $(\mathrm{OR}=1.8, \mathrm{P}<0.001)$, working in agriculture $(\mathrm{OR}=2.9, \mathrm{P}<0.001)$, having the first ANC visit after 28 weeks of gestation $(\mathrm{OR}=4.9, \mathrm{P}<0.001)$ and poor knowledge about IPTp $(\mathrm{OR}=1.6, \mathrm{P}<0.001)$, were associated with uptake of $<3$ IPTp-SP doses, while being aged $<20$ year old $(\mathrm{OR}=0.7, \mathrm{P}=0.018)$ and primigravidae $(\mathrm{OR}=0.7, \mathrm{P}=0.002)$ were associated with uptake of $\geq 3$ IPTp-SP doses. However, in the multivariate analysis women with non-institutional delivery $(\mathrm{AOR}=2.9, \mathrm{P}<0.001)$, having no or only primary education $(\mathrm{AOR}=1.3, \mathrm{P}=0.041)$, having the first $\mathrm{ANC}$ visit after 28 weeks of gestation $(\mathrm{AOR}=5.4, \mathrm{P}<0.001)$ and poor knowledge about IPTp-SP $(\mathrm{AOR}=1.6, \mathrm{P}<0.001)$ remained associated with low IPTp-SP uptake ( $<3$ doses).

\section{Factors associated with malaria infection at delivery}

The overall prevalence of maternal malaria infections at delivery (including peripheral and/or placental infections) was of $16.8 \%(154 / 914)$ of which $35.1 \%(54 / 154)$ had only placental infection, $46.7 \%$ (72/154) only peripheral infection and $16.8 \%(26 / 154)$ had both placental and peripheral infections. In the univariate analysis being $<20$ years old $(\mathrm{OR}=1.3, \mathrm{P}=0.012)$, living in rural areas $(\mathrm{OR}=2.0, \mathrm{P}<0.001)$ and having had malaria during pregnancy $(\mathrm{OR}=1.6, \mathrm{P}=0.039)$ were associated with increased odds of maternal malaria infection at delivery (Table 3). However, in the multivariate analysis being $<20$ years old $(\mathrm{AOR}=1.6, \mathrm{P}=0.042)$ and living in rural areas $(\mathrm{AOR}=1.9, \mathrm{P}<0.001)$ remained significantly associated with maternal malaria infection at delivery. Furthermore, primigravidae women were significantly associated with higher peripheral parasite densities $(\mathrm{P}=0.020$, Table 4$)$. Of the 914 women delivering at health facilities, $51.8 \%$ had moderate anaemia $(\geq 8$ and $<11 \mathrm{~g} / \mathrm{dL}$ ) and $6.6 \%$ had severe anaemia $(<8 \mathrm{~g} /$ $\mathrm{dL}$ ). The overall prevalence of $P$. falciparum peripheral infections at delivery was $10.7 \%$ (98/914) by qPCR, $2.7 \%$ (25/914) by light microscopy and $2.6 \%$ (24/914) by RDT. Among the 98 women with peripheral malaria infection at delivery by qPCR, $76.5 \%$ (75/98) were asymptomatic and sub-microscopic, while $21.4 \%$ (21/98) had 
Table 1 Characteristics of participants by place of delivery and association with non-institutional delivery

\begin{tabular}{|c|c|c|c|c|c|c|c|}
\hline \multirow[t]{3}{*}{ Variable } & \multirow[t]{3}{*}{$\mathbf{N}$} & \multicolumn{2}{|c|}{ Place of delivery } & \multirow[t]{3}{*}{ OR $95 \% \mathrm{Cl}$} & \multirow[t]{3}{*}{$P$ value } & \multirow[t]{3}{*}{ AOR $95 \% \mathrm{Cl}$} & \multirow[t]{3}{*}{$P$ value } \\
\hline & & $\begin{array}{l}\text { Health facility } \\
(n=914)\end{array}$ & $\begin{array}{l}\text { Home } \\
(n=227)\end{array}$ & & & & \\
\hline & & n [\%] & $\mathrm{n}[\%]$ & & & & \\
\hline \multicolumn{8}{|l|}{ Age } \\
\hline$<20$ & 380 & $345[37.8]$ & $35[15.4]$ & Ref. & & Ref. & \\
\hline$\geq 20$ & 761 & $569[62.2]$ & $192[84.6]$ & $3.3[2.2-4.8]$ & $<0.001$ & $1.3[0.5-2.2]$ & 0.712 \\
\hline \multicolumn{8}{|l|}{ Gravidity } \\
\hline Primigravidae (1) & 427 & $395[43.2]$ & $32[14.1]$ & Ref. & & Ref. & \\
\hline Multigravidae $(\geq 2)$ & 714 & $519[56.8]$ & 195 [85.9] & $4.6[3.1-6.8]$ & & $2.3[1.2-4.6]$ & 0.017 \\
\hline \multicolumn{8}{|l|}{ Place of residence } \\
\hline Urban & 806 & $731[80.0]$ & $75[33.0]$ & Ref. & & Ref. & \\
\hline Rural & 335 & $183[20.0]$ & $152[67.0]$ & $8.1[5.9-11.2]$ & $<0.001$ & $3.2[2.1-4.9]$ & $<0.001$ \\
\hline \multicolumn{8}{|l|}{ Marital status } \\
\hline Single & 294 & $236[25.8]$ & $58[25.5]$ & $0.9[0.7-1.3]$ & 0.934 & - & \\
\hline Married/cohabiting & 847 & 678 [7402] & $169[74.5]$ & Ref. & & & \\
\hline \multicolumn{8}{|l|}{ Education } \\
\hline None/primary school & 674 & $477[52.2]$ & $197[86.8]$ & $6.0[4.0-9.0]$ & $<0.001$ & $2.3[1.4-3.7]$ & $<0.001$ \\
\hline Secondary/high school & 467 & $437[47.8]$ & 30 [13.2] & Ref. & & Ref. & \\
\hline \multicolumn{8}{|l|}{ Occupation } \\
\hline Unemployed & 882 & $802[87.6]$ & $80[35.2]$ & $1.4[0.5-3.7]$ & 0.414 & $1.3[0.5-3.6]$ & 0.503 \\
\hline Agro-livestock & 180 & $38[4.2]$ & $142[62.6]$ & $55.3[20-146]$ & $<0.001$ & $21.2[7.6-59.1]$ & $<0.001$ \\
\hline Employed/self employed & 79 & $74[8.1]$ & $5[2.2]$ & Ref. & & Ref. & \\
\hline \multicolumn{8}{|l|}{ Bed net use } \\
\hline Yes & 1055 & 844 [92.3] & $211[92.9]$ & Ref. & & & \\
\hline No & 86 & $70[7.7]$ & $16[7.1]$ & $0.9[0.5-1.6]$ & 0.755 & - & \\
\hline \multicolumn{8}{|c|}{ Timing of first ANC visit (weeks) } \\
\hline$<28$ & 1055 & $841[92.0]$ & 214 [94.3] & Ref. & & & \\
\hline$\geq 28$ & 86 & $73[8.0]$ & $13[5.7]$ & $0.6[0.3-1.2]$ & 0.251 & - & \\
\hline \multicolumn{8}{|l|}{ Reported malaria pregnancy } \\
\hline No & 1001 & 810 [88.6] & $191[84.1]$ & Ref. & & Ref. & \\
\hline Yes & 140 & $104[11.3]$ & 36 [15.9] & $1.4[0.9-2.2]$ & 0.067 & $1.3[0.7-2.2]$ & 0.338 \\
\hline \multicolumn{8}{|l|}{ Ever heard about IPTp-SP } \\
\hline Yes & 251 & $713[78.0]$ & $177[77.9]$ & Ref. & & & \\
\hline No & 890 & $201[22.0]$ & $50[22.1]$ & $1.0[0.7-1.4]$ & 0.991 & - & \\
\hline
\end{tabular}

$\mathrm{Cl}$ confidence interval, $A N C$ antenatal care, $O R$ odds ratio, $A O R$ adjusted odds ratio, Ref. reference category

Significant $P$ values are presented in italics

asymptomatic and microscopic infections and only $2.0 \%$ (2/98) were symptomatic with sub-microscopic infections. Parasite densities ranged from 0.04 to 80,160 parasites $/ \mu \mathrm{L}$ with a median density of 2.3 [0.3-362] parasites $\mu \mathrm{L}$. The median of parasite density among mothers with asymptomatic infection was 1.9 [0.2-353] parasites/ $\mu \mathrm{L}$, compared to 824 [3.0-1646] parasites/ $\mu \mathrm{L}$ of those with symptomatic infection $(\mathrm{P}=0.410)$. The median of parasite density in mothers receiving $<3$ doses of IPTp-SP was 8.4 [0.1-104] parasites/ $\mu \mathrm{L}$ compared to 1.8 [0.2-454] parasites/ $\mu \mathrm{L}$ in those mothers receiving $\geq$ 3 doses $(\mathrm{P}=0.454)$. Placental malaria infections $(\mathrm{PM})$ by histology were detected in $8.8 \%$ (80/914) of women, from which $15.0 \%(12 / 80)$ were active infections and $85.0 \%$ $(68 / 80)$ were past infections. Nearly half of mothers with PM 43.8\% (35/80) were $<20$ years and primigravidae, and $32.5 \%(26 / 80)$ had also peripheral parasitaemia. Among the 80 mothers with PM 6.3\% (5/80) did not receive IPTpSP at all, 16.3\% (13/80) received one dose, 27.5\% (22/80) received two doses and 50.0\% (40/80) received $\geq 3$ doses, and was not significantly different from mothers with no PM (6.6\% (8/34) did not receive IPTp-SP, 16.3\% (13/834) received one dose, $28.8 \%(240 / 834)$ received two doses and $52.5 \%(438 / 834)$ received $\geq 3$ doses $(\mathrm{P}=0.784))$. 
Table 2 Characteristics of participants according to IPTp-SP dose and factors associations with low ( $<3$ doses) IPTp-SP uptake

\begin{tabular}{|c|c|c|c|c|c|c|c|c|c|}
\hline \multirow[t]{3}{*}{ Variable } & \multirow{2}{*}{$\begin{array}{l}\text { Total } \\
{[N=1.141]}\end{array}$} & \multicolumn{4}{|l|}{ IPTp doses } & \multirow[t]{3}{*}{ OR $95 \% \mathrm{Cl}$} & \multirow[t]{3}{*}{$P$ value } & \multirow[t]{3}{*}{ AOR $95 \% \mathrm{Cl}$} & \multirow[t]{3}{*}{$P$ value } \\
\hline & & $\begin{array}{l}\text { None } \\
{[n=110]}\end{array}$ & $\begin{array}{l}\text { One } \\
{[n=154]}\end{array}$ & $\begin{array}{l}\text { Two } \\
{[n=345]}\end{array}$ & $\begin{array}{l}\geq 3 \\
{[n=532]}\end{array}$ & & & & \\
\hline & n [\%] & n [\%] & n [\%] & n [\%] & n [\%] & & & & \\
\hline \multicolumn{10}{|l|}{ Age (years) } \\
\hline Median [IQR] & 22 [19-28] & $25[20-35]$ & 22 [18-28] & 22 [19-28] & 21 [18-27] & & & & $<0.001$ \\
\hline$<20$ & $380[33.3]$ & $21[5.5]$ & $57[15.0]$ & $106[27.9]$ & $196[51.6]$ & $0.7[0.6-0.9]$ & 0.018 & $0.9[0.7-1.4]$ & 0.809 \\
\hline$\geq 20$ & $761[66.7]$ & $89[11.7]$ & 97 [12.7] & $239[31.4]$ & $336[44.2]$ & Ref. & & Ref. & \\
\hline \multicolumn{10}{|l|}{ Gravidity } \\
\hline Median [IQR] & $2[1-4]$ & $3[2-5]$ & $2[1-3]$ & $2[1-4]$ & $2[1-3]$ & & & & $<0.001$ \\
\hline Primigravidae (1) & $427[37.4]$ & $20[4.6]$ & 55 [12.9] & $127[29.7]$ & $225[52.7]$ & $0.7[0.5-0.8]$ & 0.002 & $0.9[0.6-1.4]$ & 0.864 \\
\hline Multigravidae $(\geq 2)$ & $714[62.6]$ & 90 [12.6] & 99 [13.9] & $218[30.5]$ & $307[43.0]$ & Ref. & & Ref. & \\
\hline \multicolumn{10}{|l|}{ Place of delivery } \\
\hline Health facility & $914[80.0]$ & $59[7.3]$ & 115 [12.6] & $262[28.7]$ & $478[52.3]$ & Ref. & & Ref. & \\
\hline Non-institutional (home) & $227[20.0]$ & $51[15.2]$ & $39[17.2]$ & $83[37.1]$ & $54[23.8]$ & $3.5[2.5-4.8]$ & $<0.001$ & $2.9[1.8-4.5]$ & $<0.001$ \\
\hline \multicolumn{10}{|l|}{ Place of residence } \\
\hline Urban & $806[70.6]$ & $59[7.3]$ & 107 [13.3] & $232[28.8]$ & $408[50.6]$ & & & Ref. & \\
\hline Rural & $335[29.4]$ & $51[15.2]$ & $47[14.0]$ & $113[33.8]$ & $124[37.0]$ & $1.7[1.3-2.3]$ & $<0.001$ & $1.2[0.8-1.7]$ & 0.205 \\
\hline \multicolumn{10}{|l|}{ Marital status } \\
\hline Single & $294[74.2]$ & $36[12.2]$ & 39 [13.3] & 91 [31.0] & $128[43.5]$ & $1.2[0.9-1.5]$ & 0.218 & - & \\
\hline Married/cohabiting & $847[25.8]$ & $74[8.7]$ & 115 [13.6] & $254[30.0]$ & $404[47.7]$ & Ref. & & & \\
\hline \multicolumn{10}{|l|}{ Education } \\
\hline None/primary school & $674[59.1]$ & 87 [12.9] & $107[15.9]$ & $207[30.7]$ & $237[40.5]$ & $1.8[1.4-2.3]$ & $<0.001$ & $1.3[1.0-1.7]$ & 0.041 \\
\hline Secondary/high school & $467[40.9]$ & $23[4.9]$ & $47[10.1]$ & $138[29.6]$ & $259[55.5]$ & Ref. & & Ref. & \\
\hline \multicolumn{10}{|l|}{ Occupation } \\
\hline Unemployed & $882[77.3]$ & $65[7.4]$ & $110[12.5]$ & 264 [29.9] & $443[50.2]$ & $1.1[0.6-1.7]$ & 0.776 & $1.0[0.6-1.7]$ & 0.942 \\
\hline Agro-livestock & $180[15.8]$ & 38 [21.1] & $31[17.2]$ & $63[35.0]$ & $48[26.7]$ & $2.9[1.7-5.1]$ & $<0.001$ & $1.1[0.6-2.2]$ & 0.750 \\
\hline Employed/self employed & $79[6.9]$ & 7 [8.9] & $13[16.4]$ & 18 [22.8] & $41[51.9]$ & Ref. & & Ref. & \\
\hline \multicolumn{10}{|l|}{ Bed net use } \\
\hline Yes & $1055[92.5]$ & $95[9.0]$ & $146[13.8]$ & $316[30.0]$ & $498[47.2]$ & Ref. & & Ref. & \\
\hline No & $86[7.5]$ & 15 [17.5] & $8[9.3]$ & $29[33.7]$ & $34[39.5]$ & $1.3[0.9-2.1]$ & 0.172 & $1.3[0.8-2.1]$ & 0.328 \\
\hline \multicolumn{10}{|l|}{ Timing of first ANC visit } \\
\hline$<28$ weeks & $1055[92.5]$ & $96[9.1]$ & $132[12.5]$ & $309[29.3]$ & $518[49.1]$ & Ref. & & Ref. & \\
\hline$\geq 28$ weeks & $86[7.5]$ & 14 [16.3] & $22[25.6]$ & $36[41.9]$ & $14[16.3]$ & $4.9[2.7-8.9]$ & $<0.001$ & $5.4[2.9-9.8]$ & $<0.001$ \\
\hline \multicolumn{10}{|c|}{ Reported malaria pregnancy } \\
\hline No & $1001[87.7]$ & $95[9.5]$ & $131[13.1]$ & 309 [30.9] & $466[46.5]$ & Ref. & & & \\
\hline Yes & $140[12.3]$ & 15 [10.7] & $23[16.4]$ & 36 [25.7] & $66[47.2]$ & $0.9[0.7-1.4]$ & 0.896 & - & \\
\hline \multicolumn{10}{|l|}{ Ever heard about IPTp-SP } \\
\hline Yes & $251[22.0]$ & 49 [19.5] & 38 [15.1] & 70 [27.9] & 94 [37.5] & Ref. & & Ref. & \\
\hline No & 890 [78.0] & 61 [6.9] & 116 [13.0] & 275 [30.9] & 438 [49.2] & $1.6[1.2-2.2]$ & $<0.001$ & $1.6[1.2-2.2]$ & 0.002 \\
\hline
\end{tabular}

IQR interquartile range, $A N C$ antenatal care, $C l$ confidence interval, $O R$ odds ratio, $A O R$ adjusted odds ratio, Ref. reference category

Significant $P$ values are presented in italics

Factors associated with maternal anaemia, LBW infants and premature deliveries

Overall, 7.7\% (70/914) mothers delivered LBW infants, $20.8 \%$ (190/914) women had preterm deliveries and $1.1 \%$ (10/914) stillbirths. The median birth weight in the study population was $3025(2800-3400) \mathrm{g}, 38.6 \%(27 / 70)$ of LBW infants were pre-term deliveries. The gestational age of women with preterm delivered babies ranged from 22 to 36 weeks with a mean of $34.7 \pm 2.25$ weeks. Factors associated with LBW and premature delivery 
Table 3 Factors associated with malaria infection (peripheral and/or placental) among delivering women in the health facility survey $(\mathrm{N}=914)$

\begin{tabular}{|c|c|c|c|c|c|c|}
\hline \multirow[t]{2}{*}{ Potential factors } & \multicolumn{5}{|c|}{ Maternal malaria infection any (peripheral and/or placental) } & \multirow[t]{2}{*}{$P$ value } \\
\hline & $\mathbf{N}$ & $\begin{array}{l}\text { Infected } \\
\mathrm{n}[\%]\end{array}$ & OR $95 \% \mathrm{Cl}$ & $P$ value & AOR $95 \% \mathrm{Cl}$ & \\
\hline \multicolumn{7}{|l|}{ Age (years) } \\
\hline$<20$ & 345 & $72[20.9]$ & $1.3[0.9-1.9]$ & 0.012 & $1.6[1.0-2.8]$ & 0.042 \\
\hline$\geq 20$ & 569 & $82[14.4]$ & Ref. & & Ref. & \\
\hline \multicolumn{7}{|l|}{ Gravidity } \\
\hline Primigravidae (1) & 395 & $76[19.2]$ & $1.3[0.9-1.9]$ & 0.093 & $0.9[0.5-1.5]$ & 0.727 \\
\hline Multigravidae $(\geq 2)$ & 519 & $78[15.0]$ & Ref. & & Ref. & \\
\hline \multicolumn{7}{|l|}{ Residence location } \\
\hline Urban & 731 & $107[14.6]$ & Ref. & & Ref. & \\
\hline Rural & 183 & $47[25.7]$ & $2.0[1.4-2.9]$ & $<0.001$ & $1.9[1.3-2.9]$ & $<0.001$ \\
\hline \multicolumn{7}{|l|}{ Marital status } \\
\hline Single & 236 & 44 [18.6] & $1.2[0.8-1.7]$ & 0.393 & - & - \\
\hline Married/cohabiting & 678 & $110[16.2]$ & Ref. & & & \\
\hline \multicolumn{7}{|l|}{ Education } \\
\hline None/primary school & 477 & $78[16.4]$ & $0.9[0.6-1.3]$ & 0.675 & - & - \\
\hline Secondary/high school & 437 & $76[17.4]$ & Ref. & & & \\
\hline \multicolumn{7}{|l|}{ Malaria in pregnancy } \\
\hline No & 810 & 129 [15.9] & Ref. & & Ref. & \\
\hline Yes & 104 & $25[24.0]$ & $1.6[1.0-2.7]$ & 0.039 & $1.5[0.9-2.5]$ & 0.093 \\
\hline \multicolumn{7}{|l|}{ IPTp-SP receipt } \\
\hline$<3$ doses & 436 & 69 [15.8] & $0.8[0.6-1.2]$ & 0.430 & - & - \\
\hline$\geq 3$ doses & 478 & $85[17.8]$ & Ref. & & & \\
\hline \multicolumn{7}{|l|}{ Anemia $(<11 \mathrm{~g} / \mathrm{dL})^{\mathrm{a}}$} \\
\hline Yes & 470 & $76[16.2]$ & $0.9[0.6-1.3]$ & 0.560 & - & - \\
\hline No & 437 & 77 [17.6] & Ref. & & & \\
\hline \multicolumn{7}{|l|}{ Bed net use } \\
\hline Yes & 844 & $142[16.8]$ & Ref. & & & \\
\hline
\end{tabular}

$\mathrm{Cl}$ confidence interval, $O R$ odds ratio, $A O R$ adjusted odds ratio, Ref. reference category

a Data was unavailable in seven participants $(n=907)$

Significant $P$ values are presented in italics

were assessed by univariate and multivariate regression analysis (Table 5). Gravidity $(\mathrm{AOR}=2.2, \mathrm{P}=0.023)$ and pre-term delivery $(\mathrm{AOR}=2.6, \mathrm{P}<0.001)$ remained independently associated with LBW in the multivariate analysis. Moreover, receiving $<3$ doses of IPTp-SP $(\mathrm{OR}=1.3, \mathrm{P}=0.044)$ predicted premature delivery in the univariate analysis, although this association was not significant after adjusting by the other covariates. Only being $<20$ years old was independently associated with premature delivery in the multivariate analysis $(\mathrm{AOR}=1.4, \mathrm{P}=0.031)$.

\section{Discussion}

This study was conducted to evaluated the coverage of IPTp-SP in Chókwè district since the implementation of the new WHO recommendations. Importantly, estimates were assessed both in health facilities and in the community (women with non-institutional deliveries), which allowed us to accurately investigate the factors affecting IPTp uptake under routine circumstances in women with different access to health facilities. Results show that the coverage of $\geq 3$ doses of IPTp-SP is of $46.6 \%$ in the study population. The coverage of the recommended dosing was higher than estimates from the $2015 \mathrm{HH}$ survey in the Gaza province $37.2 \%$ [22], reflecting geographical variations in the coverage of IPTp-SP within the province. Moreover, the current coverage is still far below the national target of $80 \%$ of pregnant women [30]. The majority of African countries have adopted a policy of providing $\geq 3$ doses of IPTp to pregnant women, however, coverage estimates remain far below global targets [31, 32]. In 2014-2016, the overall percentage of women 
Table 4 Analysis of factors associated with higher mean peripheral parasite density among delivering women in the health facility survey

\begin{tabular}{|c|c|c|c|c|c|}
\hline \multirow[t]{2}{*}{ Potential factors } & \multirow{2}{*}{$\begin{array}{l}\text { Mean } \\
\text { Parasite density } \pm S D\end{array}$} & \multicolumn{2}{|l|}{ Coefficient } & \multicolumn{2}{|l|}{ Coefficient } \\
\hline & & $95 \% \mathrm{Cl}$ & $P$ value & $95 \% \mathrm{Cl}$ & $P$ value \\
\hline \multicolumn{6}{|l|}{ Age (years) } \\
\hline$<20$ & $8276 \pm 19,958$ & $6495[507-12,483]$ & 0.034 & $-2089[-10,606$ to 6428$]$ & 0.627 \\
\hline$\geq 20$ & $1781 \pm 8980$ & Ref. & & Ref. & \\
\hline \multicolumn{6}{|l|}{ Gravidity } \\
\hline Primigravidae (1) & $9473 \pm 21,336$ & $8952[3122-14,782]$ & 0.003 & $9832[1572-18,093]$ & 0.020 \\
\hline Multigravidae $(\geq 2)$ & $520 \pm 1526$ & Ref. & & Ref. & \\
\hline \multicolumn{6}{|l|}{ Residence location } \\
\hline Urban & $4299 \pm 14,209$ & Ref. & & & \\
\hline Rural & $5178 \pm 16,642$ & $878[-5394$ to 7152$]$ & 0.782 & - & - \\
\hline \multicolumn{6}{|l|}{ Education } \\
\hline None/primary school & $5742 \pm 17,126$ & $2176[-3893$ to 8247$]$ & 0.478 & - & - \\
\hline Secondary/high school & $3565 \pm 12,937$ & Ref. & & & \\
\hline \multicolumn{6}{|l|}{ IPTp-SP receipt } \\
\hline$<3$ doses & $4991 \pm 16,174$ & -819 [- 6948 to 5309] & 0.791 & - & - \\
\hline$\geq 3$ doses & $4171 \pm 13,767$ & Ref. & & & \\
\hline \multicolumn{6}{|l|}{ Bed net use } \\
\hline Yes & $4366 \pm 14,784$ & Ref. & & & \\
\hline No & $8703 \pm 20,521$ & $4337[-8323$ to 16,997$]$ & 0.498 & - & - \\
\hline
\end{tabular}

$S D$ standard deviation, $\mathrm{Cl}$ confidence interval, Ref. reference category

Significant $P$ values are presented in italics

who received $\geq 3$ doses of IPT-SP during pregnancy in sub-Saharan Africa ranged from 13 to $19 \%$ [32], while in recent studies, IPTp-SP coverage ranged from 6 to 87.3\% [33-35]. Non-institutional deliveries were strongly associated with low IPTp uptake in the study population living in rural areas (67\%), while the major reasons for delivering outside health facilities were lack of transport (55\%) and unexpected delivery date (40.9\%). None or only primary education, late timing of first ANC visit and poor awareness about IPTp were also associated with low IPTp uptake, similar to what has been observed in other sub-Saharan Africa countries [34, 36, 37].

At the beginning of the study, it was hypothesized that women with non-institutional deliveries would be those at higher risk of low IPTp uptake due to lower number or later initiation of ANC visits [16, 17]. Since IPTp-SP in Mozambique is delivered free of charge to pregnant women under DOT during ANC visits, the earlier the ANC visits start, the higher is the chance to receive adequate IPTp-SP dosage. Moreover, early and regular ANC attendance provides time for antenatal health education about malaria preventive strategies during pregnancy. However, in the study population, although the odds of failing to take the recommended IPTp-SP doses was five times higher among women initiating ANC visits during the third trimester of gestation compared to those starting during the first or second trimester, significant differences in time to first ANC visit between women delivering in hospital facilities and with non-institutional deliveries were not observed ( $94.3 \%$ of women with noninstitutional deliveries and $92 \%$ of women delivering at health facilities -reference and peripheral health facilities- had the first ANC visit during the first or second trimester of pregnancy). Future studies should investigate the proportion of ANC visits occurring during the first trimester of pregnancy, as is recommended by WHO in order to maximize the chances for IPTp-SP uptake [8].

Other studies have shown that barriers to adequate health (quality) care access decrease opportunities to adequate IPTp uptake [10, 38]. Although, no SP stockouts in the study area have been documented by the MoH in Maputo since 2013 (Chókwè district health services 2016, unpublished data), it is possible that women at ANC visits were not always supplied with IPTp-SP, as has been reported in previous studies in SSA $[11,38]$.

Awareness about IPTp-SP and education level were also critical factors influencing the uptake of IPTp-SP in Chókwè district, as observed in similar previous studies from other East African countries [36, 39]. These results confirm that health education on IPTp-SP and promoting formal general education beyond primary school will apprise and influence decisions and further increase 


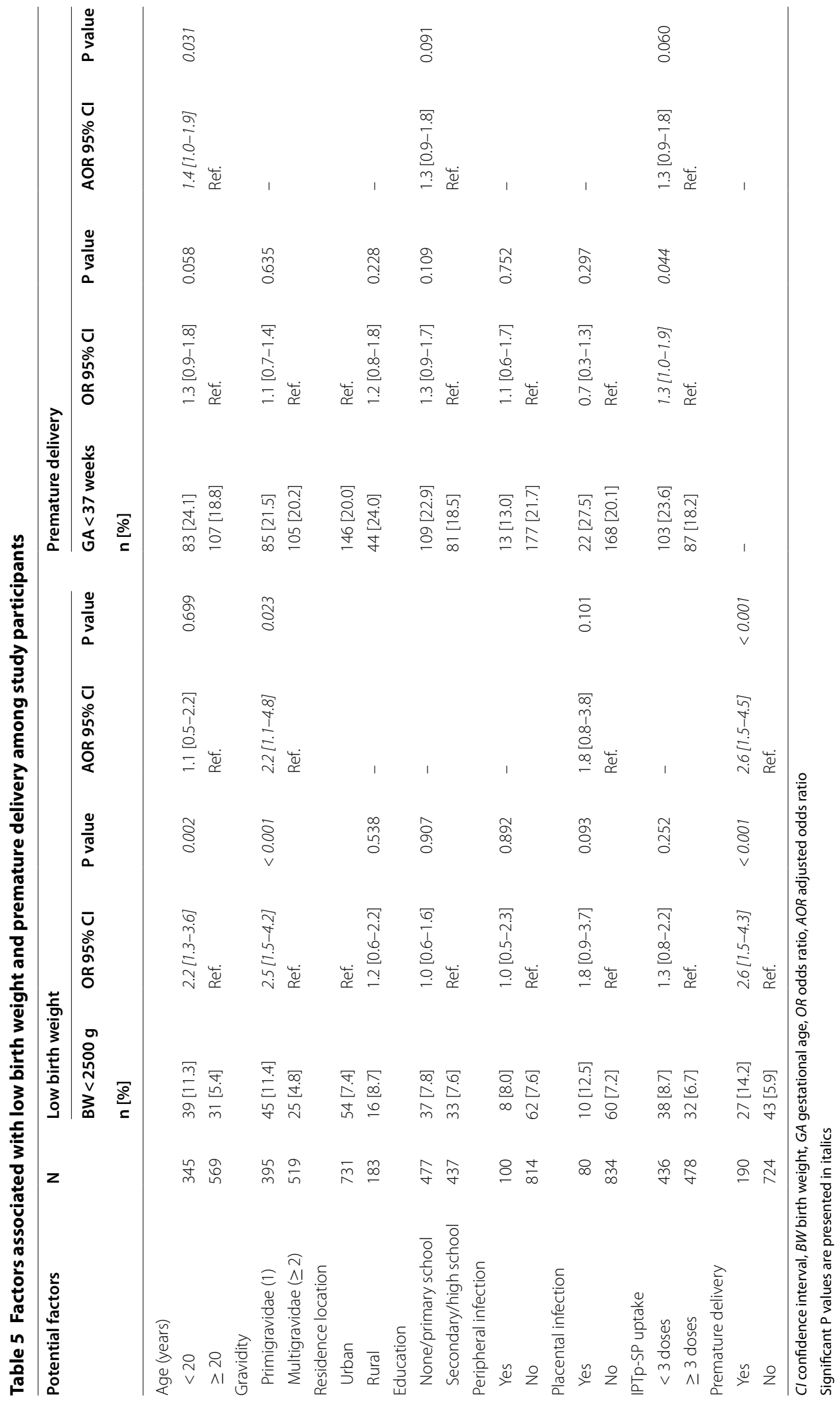


coverage of the recommended dosing among pregnant women.

The prevalence of maternal $P$. falciparum infection at delivery (defined as peripheral or placental infection) was $16.8 \%$, considerably lower than that of $23.2 \%$ reported in the neighbor district of Manhiça in 2009 [40], but is higher than the $6 \%$ reported among delivering women in the same area in 2012 [41]. In other African countries with stable transmission, the prevalence of infection at delivery ranged from 8.1 to $57.8 \%$ [42-45]. The major factor associated with infection at delivery in this study was living in rural areas. Rural villages in the area are at higher proximity to irrigation systems, which may provide additional breeding sites for mosquitoes increasing the overall risk of infection. In addition, IPTp-SP uptake is also lower in rural villages (associated with non-institutional deliveries) in concordance with other studies in Mozambique [46] and SSA [47, 48].

Although the effect of $\geq 3$ doses of IPTp-SP in reducing maternal malaria infection at delivery was non-significant, there was a trend of decreasing parasite densities with increasing number of IPTp doses indicating a benefit of higher IPTp-SP uptake on reducing parasite density $[34,49]$.

Women at their first pregnancy and at younger age ( $<20$ years) were more likely to be infected at delivery, present higher parasite densities, and give birth to LBW and pre-term infants, compared to multigravidae and older women, respectively, confirming higher susceptibility to $\mathrm{MiP}$ and related adverse effects due to inadequate pregnancy-associated immunity [7, 50-53]. Moreover, young mothers may represent a particularly disadvantaged risk group characterized by low socioeconomic status and level of education, which may have an influence on health-related behavior [54]. Therefore, higher efforts to improve uptake of IPTp in this risk group should be stressed.

The majority of infections at delivery were sub-microscopic and asymptomatic (76.5\%), which supports a role of asymptomatic pregnant women as malaria reservoir of infection and in contributing to the maintenance of malaria transmission [55, 56] (although gametocyte carriage in pregnant women should be measured to confirm this hypothesis). Sub-microscopic infections during pregnancy may have an harmful effect on the pregnant women and to the developing fetus [44, 57], however no association between infection and adverse pregnancy outcomes was observed. Although the study may have been unpowered to find significant associations in this regard, it is also well known that SP resistance affect IPTp-SP efficacy and thus, prevalence of sextuple mutated parasites in the study area should be evaluated $[58,59]$.
Placental malaria is associated with maternal and neonatal adverse outcomes in pregnancy $[4,5]$. The proportion of placental infections by histology was $8.8 \%$, the majority being past infections. The presence of PM was not correlated with peripheral infections, while similar results have been reported in other studies [52,60].

Although IPTp-SP coverage may have been overestimated since the representation of the rural population in the study is lower than that in the general population of the district, and rural women are those at higher risk of low IPTp-SP uptake, the main strengths of this study was the enrollment of women in the community and health facilities including those with non-institutional deliveries, which allowed us to accurately investigate the factors affecting IPTp uptake under routine circumstances in women with different access to health facilities and thus to IPTp-SP.

\section{Conclusion}

In conclusion, the study reports a IPTp-SP coverage for two and $\geq 3$ doses of IPTp-SP higher than estimates from a $\mathrm{HH}$ survey in the same province, but still far below the national target of $80 \%$ coverage of $\geq 3$ doses. Ongoing and new campaigns aiming to increase the use of malaria prevention strategies during pregnancy should particularly target rural populations, increasing IPTp knowledge, stimulate early visits to ANC and, importantly, improving access to health services and the quality of the services provided.

\section{Additional file}

Additional file 1: Table S1. Characteristics of the study population by delivering place and associations with non-institutional delivery.

\section{Abbreviations}

ANC: antenatal care visit; DOT: directly observed treatment; HDSS: health and demographic surveillance system; HH: household; IPTp: intermittent preventive treatment for pregnant women; ITN: insecticide-treated net; LBW: Iow birth weight; MiP: malaria in pregnancy; SP: sulfadoxine-pyrimethamine; SSA: sub-Saharan Africa.

\section{Authors' contributions}

Conceived and designed the experiments: PA, ERV, SE, LK and ARU. Performed the experiments: PA, ERV, PG, DC, JL, CS and BR. Analysed the data: PA, SE, ARU. Contributed reagents/data collection/materials/analysis tools: PA, ERV, PG, DC, $J$, CS, BR, SE, ARU. Wrote the paper: PA, SE, ARU. All authors read and approved the final manuscript.

\footnotetext{
Author details

${ }^{1}$ Department of Biomedical Sciences, Institute of Tropical Medicine Antwerp, Antwerp, Belgium. ${ }^{2}$ Plataforma de Parasitologia Molecular, Instituto Nacional de Saúde, Maputo, Mozambique. ${ }^{3}$ University of Antwerp, Antwerp, Belgium.

\section{Acknowledgements}

We sincerely thank the study participants for their cooperation and willingness to participate in this study, all staff of Chókwè Rural Hospital, Centro de Saúde do Terceiro Bairro, Centro de Saúde de Conhane, Centro de Saúde de Liónde included in the study, and district authorities of Chókwè province. Special
} 
thanks to the members of the study team, especially Olga Manuel Ngoque, Milton Muthombene, Pedro Baloi, Aristides Cabral Nhanala, Narciso Ngalambe, Katia Neves, Dulcídia Monteiro, Carlos Luís Ubice, Noe Abel Chaúque, Santos Declércio, Pedro Nuvunga, Alfredo Macuacua, Sinóida Cuinica, Kátia Camilo and João Landí Duane for their help with data collection, specimen processing, database setup and data entry. We acknowledge the support of the Chókwè Health Research and Training Centre (CITSC) and "Laboratório de histologia da Faculdade de Medicina" of Maputo Central Hospital.

\section{Competing interests}

The authors declare that they have no competing interests.

\section{Availability of data and materials}

The datasets generated and analysed during the current study are not publicly available because it contains personal participant information, but are available from the corresponding author on reasonable request.

\section{Consent for publication}

Not applicable.

\section{Ethics approval and consent to participate}

This study was approved by the National Bioethics Committees of Mozambique (CNBS)(IRB00002657), the Institute of Tropical Medicine in Antwerp (ITM) Institutional Review Board (IRBAB/ac/059) and the University of Antwerp (IRB-B300201421228). All procedures were carried out in accordance with the Helsinki Declaration as revised in 2013. Administrative approval to conduct the study was obtained from the local health facilities and the Ministry of Health of Mozambique. Informed consent was obtained at recruitment from all study participants or their representatives.

\section{Funding}

The study was funded by the Flemish International Cooperation Agency under the BICMINS project ITM-INS and Fundo Nacional de Investigação of Mozambique. PA holds a BICMINS Ph.D. scholarship.

\section{Publisher's Note}

Springer Nature remains neutral with regard to jurisdictional claims in published maps and institutional affiliations.

Received: 9 November 2017 Accepted: 3 March 2018

Published online: 12 March 2018

\section{References}

1. Diagana TT. Supporting malaria elimination with 21 st century antimalarial agent drug discovery. Drug Discov Today. 2015;20:1265-70.

2. World Health Organization. World malaria report 2016. Geneva: World Health Organization; 2016.

3. Dellicour S, Tatem AJ, Guerra CA, Snow RW, Ter Kuile FO. Quantifying the number of pregnancies at risk of malaria in 2007: a demographic study. PLoS Med. 2010;7:e1000221.

4. Eisele TP, Larsen DA, Anglewicz PA, Keating J, Yukich J, Bennett A, et al. Malaria prevention in pregnancy, birthweight, and neonatal mortality: a meta-analysis of 32 national cross-sectional datasets in Africa. Lancet Infect Dis. 2012;12:942-9.

5. Menéndez C, Bardají A, Sigauque B, Sanz S, Aponte JJ, Mabunda S, et al. Malaria prevention with IPTp during pregnancy reduces neonatal mortality. PLoS ONE. 2010;5:e9438.

6. Ayres Pereira M, Mandel Clausen T, Pehrson C, Mao Y, Resende M, Daugaard M, et al. Placental sequestration of Plasmodium falciparum malaria parasites is mediated by the interaction between VAR2CSA and chondroitin sulfate a on syndecan-1. PLoS Pathog. 2016;12:e1005831.

7. Rogerson SJ, Hviid L, Taylor DW, Rogerson SJ, Hviid L, Duffy PE, et al. Malaria in pregnancy: pathogenesis and immunity malaria in pregnancy: pathogenesis and immunity. Lancet Infect Dis. 2007;7:105-17.

8. WHO. Updated WHO policy recommendation: intermittent preventive treatment of malaria in pregnancy using sulfadoxine-pyrimethamine (IPTp-SP). Geneva: World Health Organization; 2013 [rev. January 2014]. http://www.who.int/malaria/publications/atoz/policy_brief_iptp_sp_policy_recommendation/en/. Accessed 3 Oct 2017.

9. Van Eijk AM, Hill J, Alegana VA, Kirui V, Gething PW, ter Kuile FO, et al. Coverage of malaria protection in pregnant women in sub-Saharan Africa: a synthesis and analysis of national survey data. Lancet Infect Dis. 2011;1:190-207.

10. Andrews KG, Lynch M, Eckert E, Gutman J. Missed opportunities to deliver intermittent preventive treatment for malaria to pregnant women 2003-2013: a systematic analysis of 58 household surveys in sub-Saharan Africa. Malar J. 2015;14:521.

11. Florey L. Preventing malaria during pregnancy in sub-Saharan Africa: determinants of effective IPTp delivery. DHS Analytical Studies No. 39 2013. p. 1-59.

12. Thiam S, Kimotho V, Gatonga P. Why are IPTp coverage targets so elusive in sub-Saharan Africa? A systematic review of health system barriers. Malar J. 2013;12:353.

13. Hill J, Hoyt J, van Eijk AM, D'Mello-Guyett L, ter Kuile FO, Steketee R, et al. Factors affecting the delivery, access, and use of interventions to prevent malaria in pregnancy in sub-Saharan Africa: a systematic review and meta-analysis. PLoS Med. 2013;10:e1001488.

14. Sangaré LR, Stergachis $A$, Brentlinger PE, Richardson BA, Staedke SG, Kiwuwa MS, et al. Determinants of use of intermittent preventive treatment of malaria in pregnancy: Jinja, Uganda. PLoS ONE. 2010;5:e15066.

15. Salomão C, Sacarlal J, Gudo ES. Assessment of coverage of preventive treatment and insecticide-treated mosquito nets in pregnant women attending antenatal care services in 11 districts in Mozambique in 2011: the critical role of supply chain. Malar J. 2017;16:223.

16. Simkhada B, Van Teijlingen ER, Porter M, Simkhada P. Factors affecting the utilization of antenatal care in developing countries: systematic review of the literature. J Adv Nurs. 2008;61:244-60.

17. Agadjanian V, Yao J, Hayford SR. Place, time and experience: barriers to universalization of institutional child delivery in rural Mozambique. Int Perspect Sex Reprod Health. 2016:42:21-31.

18. Ministério da Saúde (MISAU) IN de E (INE) e II (ICFI). Inquérito Demográfico e de Saúde 2011. Calverton: MISAU, INE e ICFI; 2012. p. 1-38.

19. Statistical yearbook 2016-Mozambique. National Statistic Institute; 2016.

20. MISAU. Ministério da Saúde. Programa Nacional de Controlo da Malária. Normas de manejo dos casos de malária em Moçambique. 2006.

21. PNCM. Relatório Anual do Programa Nacional de Controlo da Malária. Maputo: Direcção Nacional de Saúde Pública; 2015.

22. Ministério da Saúde (MISAU), Instituto Nacional de Estatística (INE) II. Inquérito de Indicadores de Imunização, Malária e HIV/SIDA em Moçambique 2015. Maputo, Moçambique. Rockville: INS, INE e ICF International.

23. Instituto Nacional de Estatística. Estatísticas do Distrito de Chókwè. 2010.

24. WHO. Consolidated guidelines on the use of antiretroviral drugs for treating and preventing HIV infection: recommendations for a public health approach. 2nd ed. Geneva: World Health Organization; 2016. http://www. who.int/hiv/pub/arv/arv-2016/en/. Accessed 3 Oct 2017.

25. Ballard JL, Khoury JC, Wedig K, Wang L, Eilers-Walsman BL, Lipp R. New Ballard Score, expanded to include extremely premature infants. J Pediatr. 1991;119:417-23.

26. Ministério da Saúde (MISAU). Manual Diagnóstico Laboratorial da Malária. Programa Nacional de Controlo da Malária. Maputo: Ministério da Saúde; 2011.

27. Hofmann N, Mwingira F, Shekalaghe S, Robinson LJ. Ultra-sensitive detection of Plasmodium falciparum by amplification of multi-copy subtelomeric targets. PLoS Med. 2015;12:e1001788.

28. Ordi J, Ismail MR, Ventura PJ, Kahigwa E, Hirt R, Cardesa A, et al. Massive chronic intervillositis of the placenta associated with malaria infection. Am J Surg Pathol. 1998;22:1006-11.

29. Muehlenbachs A, Fried M, McGready R, Harrington WE, Mutabingwa TK, Nosten F, et al. A novel histological grading scheme for placental malaria applied in areas of high and low malaria transmission. J Infect Dis. 2010;202:1608-16.

30. Ministério da Saúde. Plano Estratégico do Sector da Saúde PESS 2014-2019. 2013. p. 156.

31. Agarwal K, Alonso P, Chico RM, Coleman J, Dellicour S, Hill J, et al. Global call to action to scale-up coverage of intermittent preventive treatment of malaria in pregnancy: seminar report. Malar J. 2015;14:206. 
32. WHO. World malaria report 2017. Geneva: World Health Organization; 2017.

33. Kalubula M, Li XF. An assessment of utilization of intermittent preventive treatment of malaria among pregnant women in Lusaka Province of Zambia. Epidemiol Open Access. 2016;6:236.

34. Mpogoro FJ, Matovelo D, Dosani A, Ngallaba S, Mugono M, Mazigo HD. Uptake of intermittent preventive treatment with sulphadoxinepyrimethamine for malaria during pregnancy and pregnancy outcomes: a cross-sectional study in Geita district, North-Western Tanzania. Malar J. 2014;13:455.

35. Owusu-Boateng I, Anto F. Intermittent preventive treatment of malaria in pregnancy: a cross-sectional survey to assess uptake of the new sulfadoxine-pyrimethamine five dose policy in Ghana. Malar J. 2017;16:323.

36. Exavery A, Mbaruku G, Mbuyita S, Makemba A, Kinyonge IP, Kweka H. Factors affecting uptake of optimal doses of sulphadoxine-pyrimethamine for intermittent preventive treatment of malaria in pregnancy in six districts of Tanzania. Malar J. 2014;13:22.

37. Hill J, Kayentao K, Toure M, Diarwara S, Bruce J, Smedley J, et al. Effectiveness of antenatal clinics to deliver intermittent preventive treatment and insecticide treated nets for the control of malaria in pregnancy in Mali: a household survey. PLoS ONE. 2014;9:e92102.

38. Hurley EA, Harvey SA, Rao N, Diarra NH, Klein MC, Diop Sl, et al. Underreporting and missed opportunities for uptake of intermittent preventative treatment of malaria in pregnancy (IPTp) in Mali. PLoS ONE. 2016;11:e0160008.

39. Odongo CO, Bisaso RK, Byamugisha J, Obua C. Intermittent use of sulphadoxine-pyrimethamine for malaria prevention: a cross-sectional study of knowledge and practices among Ugandan women attending an urban antenatal clinic. Malar J. 2014;13:399.

40. Mayor A, Serra-Casas E, Bardaji A, Sanz S, Puyol L, Cistero P, et al. Submicroscopic infections and long-term recrudescence of Plasmodium falciparum in Mozambican pregnant women. Malar J. 2009;8:9.

41. Mayor A, Bardají A, Macete E, Nhampossa T, Fonseca AM, González R, et al. Changing trends in P. falciparum burden, immunity, and disease in pregnancy. N Engl J Med. 2015;373:1607-17.

42. Chaponda EB, Chandramohan D, Michelo C, Mharakurwa S, Chipeta J, Chico RM. High burden of malaria infection in pregnant women in a rural district of Zambia: a cross-sectional study. Malar J. 2015;14:380.

43. Rantala A, Taylor SM, Trottman PA, Luntamo M, Mbewe B, Maleta K, et al. Comparison of real-time PCR and microscopy for malaria parasite detection in Malawian pregnant women. Malar J. 2010;9:269.

44. Cohee LM, Kalilani-Phiri L, Boudova S, Joshi S, Mukadam R, Seydel KB, et al. Submicroscopic malaria infection during pregnancy and the impact of intermittent preventive treatment. Malar J. 2014;13:274.

45. Mutagonda RF, Kamuhabwa AAR, Minzi OMS, Massawe SN, Maganda BA, Aklillu E. Malaria prevalence, severity and treatment outcome in relation to day 7 lumefantrine plasma concentration in pregnant women. Malar J. 2016;15:278.

46. Saute F, Menendez C, Mayor A, Aponte J, Gomez-Olive X, Dgedge M, et al. Malaria in pregnancy in rural Mozambique: the role of parity, submicroscopic and multiple Plasmodium falciparum infections. Trop Med Int Health. 2002;7:19-28.

47. De Beaudrap P, Turyakira E, White LJ, Nabasumba C, Tumwebaze B, Muehlenbachs $A$, et al. Impact of malaria during pregnancy on pregnancy outcomes in a Ugandan prospective cohort with intensive malaria screening and prompt treatment. Malar J. 2013;12:139.

48. Ndeserua R, Juma A, Mosha D, Chilongola J. Risk factors for placental malaria and associated adverse pregnancy outcomes in Rufiji, Tanzania: a hospital based cross sectional study. Afr Health Sci. 2015;15(3):810-8.

49. Kayentao K, Garner P, van Eijk AM, Naidoo I, Roper C, Mulokozi A, et al. Intermittent preventive therapy for malaria during pregnancy using 2 vs 3 or more doses of sulfadoxine-pyrimethamine and risk of low birth weight in Africa: systematic review and meta-analysis. JAMA. 2013;309:594-604.

50. Cisse M, Diallo AH, Somé AD, Poda A, Awandare AG, Guiguemdé TR. Association of placental Plasmodium falciparum parasitaemia with maternal and newborn outcomes in the periurban area of Bobo-Dioulasso, Burkina Faso. Parasitol Open. 2016;2:e15

51. Vanga-Bosson HA, Coffie PA, Kanhon S, Sloan C, Kouakou F, Eholie SP, et al. Coverage of intermittent prevention treatment with sulphadoxinepyrimethamine among pregnant women and congenital malaria in Côte d'Ivoire. Malar J. 2011;10:105.

52. Van Eijk AM, Hill J, Noor AM, Snow RW, Kuile FO. Prevalence of malaria infection in pregnant women compared with children for tracking malaria transmission in sub-Saharan Africa: a systematic review and meta-analysis. Lancet Glob Health. 2015;3:e617-28.

53. Agomo CO, Oyibo WA. Factors associated with risk of malaria infection among pregnant women in Lagos, Nigeria. Infect Dis Poverty. 2013;2:19.

54. Kurth F, Bélard S, Mombo-Ngoma G, Schuster K, Adegnika AA, BouyouAkotet MK, et al. Adolescence as risk factor for adverse pregnancy outcome in central Africa - a cross-sectional study. PLoS ONE. 2010;5:e14367.

55. Boudová S, Cohee LM, Kalilani-Phiri L, Thesing PC, Kamiza S, Muehlenbachs $\mathrm{A}$, et al. Pregnant women are a reservoir of malaria transmission in Blantyre, Malawi. Malar J. 2014;13:1-8.

56. Goncalves BP, Walker PG, Cairns M, Tiono AB, Bousema T, Drakeley C. Pregnant women: an overlooked asset to Plasmodium falciparum malaria elimination campaigns? Trends Parasitol. 2017;33:510-8.

57. Cottrell G, Moussiliou A, Luty AJF, Cot M, Fievet N, Massougbodji A, et al. Submicroscopic Plasmodium falciparum infections are associated with maternal anemia, premature births, and low birth weight. Clin Infect Dis. 2015;60:1481-8.

58. Harrington WE, Mutabingwa TK, Kabyemela E, Fried M, Duffy PE. Intermittent treatment to prevent pregnancy malaria does not confer benefit in an area of widespread drug resistance. Clin Infect Dis. 2011;53:224-30.

59. Naidoo I, Roper C. Mapping 'partially resistant', 'fully resistant', and 'super resistant'malaria. Trends Parasitol. 2013;29:505-15.

60. Serra-casas E, Mayor A, Moro L, Aguilar R, Bardají A, Cistero P. How hidden can malaria be in pregnant women? Diagnosis by microscopy, placental histology, polymerase chain reaction and detection of histidine-rich protein 2 in plasma. Clin Infect Dis. 2012;54:1561-8.

\section{Submit your next manuscript to BioMed Central and we will help you at every step:}

- We accept pre-submission inquiries

- Our selector tool helps you to find the most relevant journal

- We provide round the clock customer support

- Convenient online submission

- Thorough peer review

- Inclusion in PubMed and all major indexing services

- Maximum visibility for your research

Submit your manuscript at www.biomedcentral.com/submit
BioMed Central 